\title{
EL CULTO FAMILIAR EN LA PRIMERA INFANCIA
}

\author{
Álvaro F. Rodríguez L uque, Lic. \\ Facultad de Teología \\ U niversidad Peruana U nión \\ alfer.rodriguez@teologia.edu.pe
}

Fecha de recepción: M ayo 2012

Fecha de aceptación y versión final: Julio 2012

\section{Resumen}

La educación de los hijos es un aspecto fundamental en la familia. Los primeros maestros son los padres y, como tales, tienen la responsabilidad de educar a sus hijos en los caminos del Señor, es decir, educarlos para esta vida y también para la eternidad. En el presente artículo encontrará las bases bíblicas para saber cuándo y cómo iniciar la educación de los hijos. En el Antiguo Testamento se puede encontrar el cómo realizar esta importante labor, mientras que el N uevo Testamento refiere el cuándo iniciar la educación religiosa con los hijos.

Palabras clave: Familia, culto familiar, bebés. 
La educación es el arma más poderosa que puedes usar para cambiar el mundo.

$\mathrm{N}$ elson M andela

\section{Introducción}

Empezar la vida de padres, es toda una aventura y a su vez un desafío del todo especial. La comunicación humana se transforma en un arte para descubrir las necesidades del neonato. En dicho contexto, la pregunta de muchos padres debe ser contestada. Muchos se cuestionan sobre la necesidad de hacer el culto de adoración a Dios en los primeros años de vida de un 72 niño y, sobre todo, cómo realizarlo. La respuesta que se plantea en este artículo tiene base en lo que dice la Bibliay los escritos de Elena G. de W hite.

\section{La formación espiritual}

En cuanto a la Biblia, encontramos algunos pasajes que nos ayudan a responder la inquietud planteada. En 2 Timoteo 3:15, el apóstol Pablo sostiene que Timoteo había aprendido acerca dela Escritura desdesu niñez. EI texto bíblico dice "y que desde la niñez has sabido las Sagradas Escrituras, las cuales te pueden dar la sabiduría que lleva a la sal- vación mediante la fe en Cristo Jesús". El término usado por el apóstol para niñez es $\beta$ pé́.osbrephos-. Este mismo término griego es usado en el Nuevo Testamento (NT) en siete ocasiones más, siendo su significado básico niño, bebe, tanto nacido como el que está en el vientre de su madre. ${ }^{1}$

En dos ocasiones hace referencia a un bebé antes de su nacimiento (LC 1:41, 44), en cuatro ocasiones es utilizada referencia a un niño recién nacido (LC 2:12, 16; H ch 7:19; 1 P 2:2). Solo en una ocasión el término parece no referirse a un neonato, pero si a un niño que aún depende de sus padres (LC 18:15). Incluso algunas versiones lo traduce como "niños muy pequeños".

1 Spiros Zodhiates, ed., "ßpéфos", en The Complete Word Study Dictionary: New Testament (Chattanooga, TN: AMG Publishers, 1993); S. Légase, "ßpéфos", en Exegetical Dictionary of the New Testament, ed., Horst Balz y Gerhard Schneider (Edinburgh: T \& T Clark, 1990), 1:227.

2 Entre estas versiones se tiene $L a$ Biblia de las Américas, Nueva Biblia de los Hispanos, Nueva Versión Internacional, Reina Valera Actualizada. Entre las versiones inglesas se puede ver incluso la traducción "bebes" como es el caso de la American Standard Version, The Complete Jewish Bible, English Revised 
En el Antiguo Testamento (AT) encontramos un caso especial que ilustra los principios acerca de la crianza de un niño. De hecho, se puede percibir que las instrucciones dadas a la madre sobre la crianza son un factor preponderante en la vida futura del mismo. El caso al cual se hace referencia es el de Sansón. Su madre, esposa de Manoa, recibió la visita de un ángel, quién le dijo que a pesar de su esterilidad, tendría un hijo. Para ello, no debía tomar bebidas alcohólicas ni comidas inmundas (Jue 13:3-4). Más adelante el padre, en un segundo encuentro con el ángel, solicita información sobrela crianza y modo de vida del muchacho que nacería. La respuesta fue la misma (Jue 13:13-14).

El motivo de dicha instrucción, fue que el niño Sansón, se ría nazareo desde el vientre de su madre. Ser nazareo significaba que no debería tomar vino ni licor, ni vinagre, tampoco debería tomar jugo de uva ni uvas frescas o secas. Nada que provenga de la vid debería ser ingerido por un nazareo. Además, no debería

Version, Geneva Bible, New American Standard Bible, New English Translation, New International Version, The New Jerusalem Bible, entre otras. pasar la navaja sobre su cabeza ni acercarse a cosas inmundas, como los cadáveres ( $\mathrm{N} \mathrm{m}$ 6:1-8).

A demás de esto, se puede notar que en el AT la educación de los niños, está a cargo de los padres. Dicha educación está basada en las enseñanzas de la Escritura. En Deuteronomio 6:4 encontramos la shema, texto valioso del pueblo hebreo. A continuación Dios instruyó a M oisés que estas palabras deberían ser enseñadas y repetidas en todo lugar y en todo tiempo a los hijos del pueblo hebreo (Dt 6:4-9).

Por lo que se puede notar hasta aquí, el AT hace énfasis en el cómo enseñar a un niño los caminos del Señor, mientras que el NT especifica desde cuándo. Por lo tanto, a la luz de la Escritura, la instrucción de un niño en el conocimiento de Dios se da inicio desde antes de su nacimiento, desde el vientre de la madre. En cuando a la metodología de enseñanza, es evidente que existen dos medios para lograrlo, la repetición y el ejemplo.

Es el turno de los escritos de Elena G. de W hite. Considerando que el don profético entregado a Elena G. White es dado 
por Dios, entonces, lo que ella escribió es de carácter inspirado. La siguiente cita es referente a las implicancias de lo acaecido con la madre de Sansón:

Las palabras dirigidas a la esposa de M anoa contienen una verdad que las madres de hoy harán bien en estudiar. Al hablar a esta madre, el Señor habló a todas las madres ansiosas y afligidas de aquel tiempo, y a todas las madres de las generaciones sucesivas. Sí, cada madre puede comprender su deber. Puede saber que el carácter de sus hijos dependerá más de sus hábitos anteriores a su nacimiento y de sus esfuerzos personales después del nacimiento, que de las ventajas o desventajas exteriores. ${ }^{3}$

Según esta cita, el carácter de los hijos es el resultado de dos elementos que se conjugan en la educación de los niños. Primero, la influencia prenatal; $y$, segundo, los esfuerzos de la madre en favor de su niño una vez nacido. Si bien es cierto que aquí se habla sobre el papel de la madre, el padre no está excluido de dicha influencia, tanto por un asunto genético, como por lo

3 Elena G. White, Mente, carácter $y$ personalidad (Buenos Aires: Asociación Casa Editora Sudamericana, 2009), 1:139. que hace mientras el niño está en gestación y después de su nacimiento. ${ }^{4}$

Todas estas declaraciones sobre los elementos influyentes en un niño, tanto en la etapa prenatal como posnatal se han confirmado a la luz de diversos estudios, los cuales han sido plasmadas en trabajos referentes a la personalidad del ser humano. ${ }^{5}$ De esta manera se puede afirmar que la personalidad del ser humano, se forma no solamente desde que nace sino desde antes de su nacimiento.

4 Elena G. White sostiene que el padre también toma parte activa en la educación, tanto en la época prenatal como posnatal. Ibíd., 139-40.

5 Entre los que sostienen la influencia directa de la etapa prenatal está Mireia Bosch Pujadas, La psicología del desarrollo humano en las etapas más vulnerables e influenciables del individuo (Monografía para el departamento de filosofía del I. E. S. Mediterránea del Masnou, dictado por Manuel Barrero, enero de 2008) disponible en http:// iesmediterrania.cat/tr08/pdf/mireia\%20 bosh,\%20EL\%20DESARROLLO\%20 DE\%20LA\%20PERSONALIDAD.pdf (Consultado el 17 de junio de 2012). En cuanto a la importancia del entorno en el que se desarrolla el ser humano como medio de influencia está Adrián Cuevas Jiménez, "Derechos del niño y desarrollo infantil" Revista cubana de psicología 22, №. 1 (2005): 37-41. 
En este contexto, el desarrollo espiritual también entra en el escenario y debe ser tomado en cuenta por aquellos que están preocupados por la vida de sus hijos o por aquellos que tienen planes de hacerlo.

\section{Elementos básicos para el culto familiar}

Tomando en cuenta el programa de educación religiosa llamado E slabones de $\mathrm{G}$ racia para menores de la Iglesia Adventista del Séptimo Día y algunos documentos sobre estimulación prenatal se puede enumerar algunos elementos claves en la educación espiritual de un niño.

En primer lugar, durante la etapa prenatal, los bebes captan lo que sucede en el ambiente que los rodea. Tal percepción se basa en estímulos auditivos, visuales, motores y táctiles. ${ }^{6}$ Por 10 tanto, durante esta etapa se debe dirigir la atención a esta clase de estímulos durante el culto familiar. Esto involucra música adecuada, la voz de los padres y caricias de ambos sobre el niño que está en el vientre de la madre.

6 Diana Paricio Andrés, Estimulación prenatal (Universidad de Valencia, Facultad de Psicología) disponible en http://mural.uv.es/diapan/ (consultado: 17 de junio, 2012).
U na vez que el niño sale del ámbito intrauterino empieza la segunda fase del proceso de enseñanza espiritual del niño. En la etapa anterior se logró que el niño se familiarice con la voz de sus padres y a su vez con un momento especial del día, el culto familiar. El niño reconoce la música que se usaba mientras estaba en el vientre de mamá y ahora, al escuchar la misma música siente seguridad, pues el entorno le es familiar.

Desde el nacimiento hasta los dos años de vida, el niño tiene las siguientes características: "C recen rápidamente, se cansan fácilmente y no pueden mantenerse quietos por mucho tiempo". ${ }^{7}$ Siendo que su periodo de concentración es mínimo, es necesario que el culto familiar no sea extenso ni mucho menos cansador. Debe ser ágil, dinámico y de corta duración. No por ello debe perderse la calidad del mismo. El culto debe adecuarse plenamente a los niños de esta edad.

7 Falvo Fowler, ed., Cuna: Guía para directores y maestros (Miami, FL: Departamento de Escuela Sabática de la División Interamericana de la Iglesia Adventista del Séptimo Día, s/f), 9. 
O tra cualidad de los niños en la primera infancia, es la capacidad que ellos tienen para concentrarse en las cosas que pueden ver y tocar. ${ }^{8} \mathrm{El}$ momento de adoración a Dios en el hogar no debe ser abstracto. Al contrario, el niño necesita de elementos visuales y pal pables durante este espacio. Por lo tanto, los padres deben conseguir figuras y obje tos que se relacionen con la lección a estudiar para que el niño mantenga su atención en lo que se desarrolle en este espacio de tiempo.

D urante los tres a cinco años, la perspectiva del niño varía un poco. El tiempo de atención se incrementa a medida que crece. El tiempo en minutos de atención de un niño "equivale a su edad más uno"9. En esta etapa, a los niños les gusta explorar su entorno, por lo que una de sus principales fuentes de aprendizaje es la exploración. ${ }^{10}$ En tal sentido, las lecciones pueden

8 Ibíd.

9 Falvo Fowler, ed., Jardín de infantes: Guía para directores y maestros (Miami, FL: Departamento de Escuela Sabática de la División Interamericana de la Iglesia Adventista del Séptimo Día, s/f), 5.

\section{Ibíd., 4}

durar un poco más que en la etapa anterior, pero se requiere mayor creatividad para llevar al niño a la exploración y así al descubrimiento de cosas nuevas.

Entre otras cualidades de un niño a esta edad está la capacidad de memorizar cosas nuevas. Es bueno estimular esta actividad aun cuando no entiendan lo que están memorizando.11 Como padres, es necesario aprovechar dicha capacidad para que el niño grabe en su memoria los fundamentos de la fe bíblica. Esto se hace, tal como el texto bíblico dice, por la repetición constante (Dt 6:7). En tal sentido, la música en esta etapa es fundamental, pues este medio tiene la capacidad de grabar información en la mente del niño, incluso del adulto, en poco tiempo y a largo plazo. Esto se debe al alto nivel de influencia tanto prenatal como postnatal de la música. ${ }^{12}$

Finalmente, se debe recalcar que los niños no aprenden modelos predeterminados, los ni-

\section{Ibíd.}

12 Jorge E. León Pineda, El poder de la música: Plenitud, buena salud y gozo espiritual (Miami, FL: Christian Editing, 2011), 23. 
ños en esta edad, absorben todo lo queven y perciben sus sentidos. Por tal razón los niños imitan el modelo que ven, no el que les parece mejor. En tal sentido, los padres, el principal elemento en la formación espiritual de los niños, deben entrar en contacto con Dios para ser transformados por su gracia y así podrán inculcar no solo por precepto, sino por ejemplo, la fe que trasforma al ser humano. Dicha verdad fue expresada por Elena G. W hite el su libro Conducción del niño al declarar,

Cuando los padres cumplan cabalmente su parte, presentando línea sobre línea y precepto sobre precepto, haciendo sus lecciones cortas e interesantes, y enseñando no solo por precepto sino también por ejemplo, el Señor colaborará con sus esfuerzos y los convertirá en maestros eficientes. ${ }^{13}$

Es necesario recalcar que la labor de guiar a los hijos no termina con el culto familiar. En realidad, esta actividad es solo el inicio de la labor encargada a los padres que confían en C risto.

Guiar a los hijos que el Señor nos ha confiado como padres,

13 Elena G. White, Conducción del niño (Buenos Aires: Asociación Casa Editora Sudamericana, 2008), 23. es una labor constante. En todo momento los hijos ven a sus padres y están atentos a su comportamiento en relación con lo que dicen creer. Es responsabilidad de los padres vivir a la altura de los preceptos bíblicos. Ante tal faena, el Señor estará de parte de aquellos que estén dispuestos a vivir de parte de la verdad en cualquier circunstancia (cf. Mt 28:20).

\section{Viendo los resultados}

H ace un tiempo atrás, a decir verdad quince meses, recibimos la noticia de que estábamos, mi esposa y yo, "embarazados". Gran alegría embargó nuestro corazón. Luego de unos días, cuando la noticia fue asimilada plenamente por nosotros, mientras conversábamos, vino la preocupación en cuanto a su educación. La familia viene sufriendo embates que parecen minar la institución establecida en el Edén. Cómo hacer para educar a nuestro bebé. Leímos a Elena $\mathrm{G}$. de W hite e innumerables páginas web referentes al tema y todas al unísono nos de cían: La educación empieza ahora, no cuando tenga cinco años. Entonces empezamos, hacíamos un culto para el bebé. En ese 
momento, colocábamos música especial mientras mi esposa y yo le hablábamos al niño que cre cía. Así fue durante todo el embarazo.

Cuando Misael nació continuamos con el proceso. Podíamos ver que cuando orábamos el niño se movía, hacia ruidos, e incluso, en ocasiones, lloraba. A medida que han pasado los meses, hemos percibido que cuando hacemos el culto con Misael, él presta atención a nuestras voces. Aunque Misael todavía se mueve y hace ruidos cuando le estamos contando las historias bíblicas de la lección de Cuna, cuando oramos ya aprendió a estar en silencio, siempre que la oración sea corta. Creemos que ya entiende que estamos orando, o que realizamos al go en que él debe permanecer en silencio unos segundos. Le damos gra- cias a Dios porque nuestro hijo está creciendo sano y aprendiendo de la fe bíblica. Por lo pronto, seguimos mostrándole con nuestro ejemplo, la importancia del culto familiar en la primera infancia, al cantar y orar con M isael, preparándonos y preparándolo para el retorno de C risto.

\section{Conclusión}

En base a lo que se ha expuesto, la formación espiritual de los niños debe iniciarse desde antes de su nacimiento. Ya desde el vientre de la madre, los padres deben iniciar la educación de su hijo en los caminos de Señor. Durante los primeros cinco años, la tarea debe continuar haciendo uso de recursos visuales, auditivos y otros elementos con los cuáles el niño pueda interactuar y aprender mejor las lecciones de la Palabra de Dios. 